\title{
SELETIVIDADE INICIAL DE MESOTRIONE EM FUNÇÃO DE MODALIDADES DE APLICAÇÃO NA CULTURA DO MILHO DOCE
}

\author{
MYLLA CRYSTHYAN RIBEIRO ÁVILA ${ }^{1}$, SIDNEI DOUGLAS CAVALIERI ${ }^{2}$, \\ SERAFIM MARTINS DA CUNHA FILHO ${ }^{3}$, MATEUS FELIPE GONÇALVES ${ }^{3}$ \\ e FERNANDA SATIE IKEDA ${ }^{4}$
}

\author{
${ }^{1}$ Universidade Federal de Goiás (UFG), Goiânia, GO,Brasil-mylla_cr@hotmail.com \\ ${ }^{2}$ Embrapa Algodão, Sinop, MT, Brasil-sidnei.cavalieri@embrapa.br \\ ${ }^{3}$ Instituto Federal Goiano, Campus Morrinhos (IF Goiano), Morrinhos, GO, Brasil \\ serafimmartins@hotmail.com,felipegoncalves55@gmail.com \\ ${ }^{4}$ Embrapa Agrossilvipastoril, Sinop, MT,Brasil-fernanda.ikeda@embrapa.br
}

$\overline{\text { Revista Brasileira de Milho e Sorgo, v.16, n.3, p. 569-577, } 2017}$

\begin{abstract}
RESUMO - No Brasil, o controle químico de plantas daninhas em milho doce baseia-se em herbicidas registrados para milho comum. Objetivou-se com este trabalho avaliar, por meio de curvas de dosagem-reposta, a seletividade inicial do herbicida mesotrione ao milho doce em função de modalidades de aplicação. O experimento foi conduzido em casa de vegetação, utilizando-se delineamento experimental em blocos casualizados em esquema fatorial 5x3, com cinco repetições. Foram avaliadas cinco dosagens de mesotrione $\left(0,72,144,288\right.$ e $\left.576 \mathrm{~g} \mathrm{ha}^{-1}\right)$ e três épocas de aplicação do herbicida (pré-emergência em pós-semeadura, pós-emergência em estádio V3 e pós-emergência em estádio V6), totalizando 15 tratamentos. As avaliações foram realizadas de forma a estudar os efeitos de mesotrione relacionados a intoxicação, índice SPAD, crescimento e massa seca de parte aérea das plantas. Não foi observada interação significativa $(p<0,05)$ entre os fatores avaliados (épocas de aplicação e dosagens do herbicida) no presente estudo. O mesotrione apresenta seletividade à cultura do milho doce híbrido Tropical Plus até quatro vezes a dosagem recomendada do herbicida $\left(4 \times 144 \mathrm{~g} \mathrm{ha}^{-1}\right)$ ou $\left(576 \mathrm{~g} \mathrm{ha}^{-1}\right)$ tanto em aplicações em pré-emergência quanto em pósemergência (estádios V3 e V6).
\end{abstract}

Palavras-chave: Zea mays L. grupo saccharata, época de aplicação, fitointoxicação, herbicida, inibidor de carotenoides.

\section{INITIAL SELECTIVITY OF MESOTRIONE AS FUNCTION OF APPLICATION MODALITIES IN SWEET CORN}

\begin{abstract}
In Brazil, the chemical control of weeds in sweet corn uses herbicides registered for common corn. This study aimed at evaluate the initial selectivity of the herbicide mesotrione to sweet corn, by dosage-response curves in different application modalities. The experiment was conducted in a greenhouse with randomized blocks design in factorial scheme $5 \times 3$ and five replications. Five dosages of mesotrione $\left(0,72,144,288\right.$ and $\left.576 \mathrm{~g} \mathrm{ha}^{-1}\right)$ and three periods of application of the herbicide (pre-emergence at post-sowing, post-emergence at V3 and post-emergence at V6), with 15 treatments in total, were assessed. Assessments were carried out to analyze the effects of mesotrione related to intoxication, SPAD index, growth and biomass of the aerial part of the plants. No relevant interaction was detected in the study $(\mathrm{p}<0,05)$ between the assessed factors (periods of application and herbicide dosages). Mesotrione is selective to sweet corn hybrid Tropical Plus up to four times the recommended dosage of the herbicide $\left(4 \mathrm{x} 144 \mathrm{~g} \mathrm{ha}^{-1}\right) \mathrm{or}(576$ $\mathrm{g} \mathrm{ha}^{-1}$ ) both in pre-emergence and post-emergence applications (V3 and V6 growth stages).
\end{abstract}

Keywords: Zea mays L. group saccharata, periods of application, phyto-intoxication, herbicide, carotenoid inhibitor. 
O milho doce (Zea mays L. grupo saccharata) pertence à família Poaceae e ao gênero Zea (Nakagawa et al., 2012). O resultado de uma mutação espontânea do milho convencional resultou no milho doce, que difere do milho comum pela presença de alelos que bloqueiam a conversão de açúcares em amido no endosperma, conferindo aos grãos alto teor de açúcares e baixo teor de amido (Zuchareli et al., 2012). O milho doce é uma hortaliça de elevada importância econômica em nível mundial. No Brasil, cultivamse ao redor 36.000 ha de milho doce, e praticamente $100 \%$ da produção é destinada ao processamento industrial para consumo humano, movimentando em torno de R 5550 milhões por ano. A produção está concentrada no Estado de Goiás, que se destaca como o maior produtor, com 28.000 ha (Pereira Filho \& Teixeira, 2016).

Por ser uma hortaliça, o milho doce possui caracteres relacionados à qualidade e aos aspectos agronômicos com maior influência na aceitação comercial do que o milho comum. O controle químico de plantas daninhas representa um dos principais componentes do custo de produção do milho doce, sendo necessário para garantir a expressão de seu potencial produtivo, incluindo-se fatores de qualidade, tais como tamanho da espiga e enchimento de ponta (Williams et al., 2008). Williams (2006), realizando estudos relacionados a diferentes épocas de semeadura de milho doce no norte dos Estados Unidos e suas implicações sobre o potencial de interferência das plantas daninhas para o híbrido GH0937, semeado em espaçamento de $0,76 \mathrm{~m}$, observou que o período crítico de prevenção de interferência foi do estádio V3 a V8 de desenvolvimento da cultura.

Sem o registro específico de herbicidas para a cultura o milho doce, o produtor tem se beneficiado de práticas de manejo e controle químico de plantas daninhas desenvolvidas para utilização em milho comum. A seletividade de determinado herbicida pode variar com as condições em que é aplicado. Entre os fatores que determinam a seletividade, destacam-se os relacionados às características do herbicida ou ao método de aplicação, como dosagem, formulação, localização espacial ou temporal do herbicida em relação à planta, bem como razões relativas às características das plantas, como seletividade associada à retenção e à absorção diferencial, a seletividade associada à translocação diferencial e seletividade associada ao metabolismo diferencial (Oliveira Júnior et al., 2011).

Dentre os herbicidas registrados para aplicação em pós-emergência na cultura do milho, encontra-se o mesotrione (2-(4-mesyl-2-nitrobenzoyl) ciclohexane-1,3-dione), pertencente ao grupo químico das tricetonas (Rodrigues \& Almeida, 2011). Seu mecanismo de ação consiste na inibição da biossíntese de carotenoides por meio da interferência na atividade da enzima HPPD (4- hidroxifenil-piruvato-dioxigenase) nos cloroplastos. Os sintomas de intoxicação observados envolvem o branqueamento das plantas sensíveis, com posterior necrose e morte dos tecidos vegetais. $\mathrm{O}$ milho apresenta tolerância ao mesotrione em razão da sua capacidade de metabolizar rapidamente o herbicida, produzindo metabólitos sem atividade tóxica (Karam et al., 2010).

De acordo com O'Sullivan et al. (2002), que estudou a seletividade do herbicida mesotrione para cultivares de milho doce em diferentes épocas de aplicação, aplicações em pré-emergência do herbicida não causaram nenhum tipo de injúria a qualquer cultivar avaliada. Já para aplicação em pós-emergência, todas as cultivares avaliadas apresentaram sintomas de fitointoxicação que aumentaram gradativamente em uma escala percentual de danos visuais conforme o crescente aumento da dosagem. 
Diante dos poucos estudos acerca dos efeitos do herbicida mesotrione na cultura em condições tropicais e considerando que a seletividade do herbicida pode variar em função da dosagem aplicada e do estádio fenológico das plantas no momento da aplicação, objetivou-se com este trabalho avaliar, por meio de curvas de dosagem resposta, a seletividade do mesotrione ao milho doce em função de modalidades de aplicação.

O experimento foi conduzido no período de 21/06/2016 a 30/08/2016, em casa de vegetação do Instituto Federal Goiano, Campus Morrinhos-GO. Para a instalação do ensaio foi utilizado solo da camada de 0 a $20 \mathrm{~cm}$ de um Latossolo Vermelho Distrófico (Santos et al., 2013) de textura média franco arenosa com $67 \%$ de areia, $7 \%$ de silte e $26 \%$ de argila. A análise química do solo apresentou $\mathrm{pH} \mathrm{em} \mathrm{CaCl}_{2}: 5,7$; $\mathrm{Al}^{3+}, \mathrm{H}^{+}+\mathrm{Al}^{3+}, \mathrm{Ca}^{2+}, \mathrm{Mg}^{2+}$ e $\mathrm{K}^{+}$, de 0,$0 ; 2,6 ; 3,7 ; 1,1$; e $0,18 \mathrm{cmolc} \mathrm{dm}^{-3}$, respectivamente; P: $14,5 \mathrm{mg} \mathrm{dm}^{-3}$; e MO: $24 \mathrm{~g} \mathrm{~kg}^{-1}$. O solo foi peneirado em malha de 2 mm para separação de torrões, raízes e palha.

As unidades experimentais foram constituídas por vasos de polietileno preenchidos com $5 \mathrm{dm}^{3}$ de solo, previamente adubado conforme a análise química e a recomendação para a cultura. Os cálculos para adubação foram realizados relacionando o volume de solo contido no vaso com o volume de solo de um hectare, na profundidade de $20 \mathrm{~cm}$. Foram semeadas cinco sementes por vaso do híbrido simples Tropical Plus, a uma profundidade de aproximadamente $2 \mathrm{~cm}$. O híbrido possui alto potencial produtivo na região, de característica superdoce, ideal para consumo in natura e processamento industrial com ciclo de 90 a 110 dias. Aos dez dias após a emergência das plântulas, procedeu-se o desbaste, deixando-se apenas duas plântulas por vaso. A irrigação foi realizada diariamente, sendo programada de acordo com as condi- ções climáticas e também com relação à capacidade de campo e ao ponto de murcha permanente.

O delineamento experimental foi de blocos casualizados, em esquema fatorial $5 \times 3$, com cinco repetições. Os fatores foram constituídos por cinco dosagens do herbicida mesotrione $(0,72,144,288 \mathrm{e}$ $576 \mathrm{~g} \mathrm{ha}^{-1}$, sendo $144 \mathrm{~g} \mathrm{ha}^{-1}$ a dosagem recomendada para o milho comum) e três épocas de aplicação do herbicida (pré-emergência em pós-semeadura, pós-emergência em estádio $\mathrm{V} 3$ e pós-emergência em estádio V6), totalizando 15 tratamentos. A aplicação do herbicida foi realizada com o auxílio de pulverizador costal pressurizado com $\mathrm{CO}_{2}$, equipado com barra de quatro bicos com pontas tipo jato plano XR 110.02, espaçados de $0,5 \mathrm{~m}$ entre si e calibrados para aplicar volume de calda de $200 \mathrm{~L} \mathrm{ha}^{-1}$. Para os tratamentos em pós-emergência, foi adicionado o adjuvante Nim$\operatorname{bus}^{\circledR}(0,5 \% \mathrm{v} / \mathrm{v})$ na calda de aplicação.

As avaliações foram realizadas de forma a estudar os efeitos do mesotrione relacionados a intoxicação, índice SPAD, crescimento e massa de matéria seca da parte aérea das plantas. Realizaram-se avaliações visuais de intoxicação aos 7, 10, 14 e 21 dias após a emergência das plantas de milho doce para os tratamentos aplicados em pré-emergência (DAE-Pré) e nos mesmos intervalos de tempo após a aplicação dos tratamentos em pós-emergência (estádios V3 e V6) (DAA-Pós) por meio da escala EWRC (European Weed Research Council, 1964), em que 1 descreve plantas sem danos na parcela e 9, a morte das plantas.

Para as avaliações de índice SPAD, foram realizadas duas leituras em cada parcela adotando a última folha expandida para avaliação, utilizandose o equipamento clorofilômetro Soil Plant Analysis Development - SPAD-502 (Minolta, 1989), sendo realizadas aos 7, 10 e 21 DAE-Pré e DAA-Pós. As variáveis relacionadas ao crescimento do milho doce 
foram avaliadas aos 7, 14 e 21 DAE-Pré e DAA-Pós, nas duas plantas que constituíam a parcela, medindose a altura das plantas entre o nível do solo e a lígula da última folha expandida e o diâmetro de colmo com o auxílio de paquímetro digital no nível do solo (abaixo do epicótilo).

Ao término das avaliações aos 21 DAA-Pós nas plantas em estádio V6, foi realizada a colheita da parte aérea das plantas de cada vaso para a obtenção dos dados de massa de matéria seca. Em seguida, as plantas foram acondicionadas em sacos de papel e secas em estufa de circulação forçada de ar, na temperatura média de $60{ }^{\circ} \mathrm{C}$ até atingir massa seca constante, sendo pesadas posteriormente em balança analítica de precisão.
Para possibilitar a comparação dos resultados das avaliações de crescimento e índice SPAD, considerando as diferentes épocas de aplicação, os dados foram convertidos para valores percentuais dos tratamentos herbicidas em relação aos valores das respectivas testemunhas sem aplicação do mesotrione, considerada $100 \%$. Os dados foram submetidos aos testes de Levene e Shapiro-Wilk para avaliar a variância e a normalidade dos erros, empregando-se o programa estatístico SAS (SAS Institute, 1999). Após a análise de variância, para a análise do fator isolado época de aplicação, as médias foram comparadas pelo teste de Tukey a 5\% de probabilidade, utilizando-se o programa estatístico SISVAR (Ferreira, 1999).

Tabela 1. Resumo da análise de variância para as variáveis-resposta altura de plantas relativa (\%), diâmetro de colmo relativo (\%), índice SPAD relativo (\%) e massa seca da parte aérea (g) de plantas de milho doce híbrido Tropical Plus em resposta a dosagens crescentes de mesotrione em diferentes modalidades de aplicação. Morrinhos-GO, 2016.

\begin{tabular}{|c|c|c|c|c|c|c|}
\hline \multirow{3}{*}{ Variável-resposta } & \multirow{3}{*}{$\begin{array}{l}\text { Época de } \\
\text { avaliação }\end{array}$} & \multicolumn{3}{|c|}{ Fonte de Variação } & \multirow[b]{3}{*}{$\begin{array}{c}\text { Média } \\
\text { Geral }\end{array}$} & \multirow[b]{3}{*}{$\begin{array}{l}\mathrm{CV} \\
(\%)\end{array}$} \\
\hline & & \multicolumn{3}{|c|}{$\operatorname{Pr}>\mathrm{Fc}$} & & \\
\hline & & Época & Dosagem & $\begin{array}{c}\text { Época } \\
\text { x } \\
\text { Dosagem }\end{array}$ & & \\
\hline Altura de plantas relativa $(\%)$ & $7 \mathrm{DAA}$ & $0,57^{\mathrm{ns}}$ & $0,21^{\mathrm{ns}}$ & $0,93^{\text {ns }}$ & 103,45 & 9,35 \\
\hline Altura de plantas relativa $(\%)$ & $14 \mathrm{DAA}$ & $0,12^{\text {ns }}$ & $0,38^{\text {ns }}$ & $0,98^{\mathrm{ns}}$ & 97,44 & 9,55 \\
\hline Altura de plantas relativa $(\%)$ & $21 \mathrm{DAA}$ & $0,00 *$ & $0,52^{\mathrm{ns}}$ & $0,49^{\mathrm{ns}}$ & 99,73 & 9,17 \\
\hline Diâmetro de colmo relativo (\%) & $7 \mathrm{DAA}$ & $0,43^{\text {ns }}$ & $0,37^{\text {ns }}$ & $0,75^{\mathrm{ns}}$ & 97,46 & 10,24 \\
\hline Diâmetro de colmo relativo (\%) & $14 \mathrm{DAA}$ & $0,00 *$ & $0,13^{\text {ns }}$ & $0,42^{\text {ns }}$ & 100,78 & 8,46 \\
\hline Diâmetro de colmo relativo (\%) & $21 \mathrm{DAA}$ & $0,00 *$ & $0,11^{\mathrm{ns}}$ & $0,20^{\mathrm{ns}}$ & 102,12 & 6,79 \\
\hline Índice SPAD relativo (\%) & $7 \mathrm{DAA}$ & $0,33^{\mathrm{ns}}$ & $0,95^{\mathrm{ns}}$ & $0,92^{\mathrm{ns}}$ & 100,30 & 10,06 \\
\hline Índice SPAD relativo (\%) & 10 DAA & $0,00 *$ & $0,10^{\mathrm{ns}}$ & $0,55^{\mathrm{ns}}$ & 106,24 & 9,46 \\
\hline Índice SPAD relativo (\%) & $21 \mathrm{DAA}$ & $0,14^{\mathrm{ns}}$ & $0,95^{\mathrm{ns}}$ & $0,85^{\mathrm{ns}}$ & 99,72 & 8,98 \\
\hline Massa seca de parte aérea $(\mathrm{g})$ & Colheita & $0,81^{\mathrm{ns}}$ & $0,55^{\mathrm{ns}}$ & $0,93^{\mathrm{ns}}$ & 16,54 & 19,26 \\
\hline
\end{tabular}

ns: Não significatívo pelo teste $\mathrm{F}$ a $5 \%$ de probabilidade $(\mathrm{p}<0,05)$.

*: Significativo pelo teste $\mathrm{F}$ a $5 \%$ de probabilidade $(\mathrm{p}<0,05)$. 
Não houve interação entre os fatores épocas de aplicação e dosagens de mesotrione para nenhuma das variáveis-resposta avaliadas no experimento $(p<0,05)$. Todavia, houve efeito isolado do fator época de aplicação para as variáveis-resposta altura de plantas aos 21 DAA, diâmetro de colmo aos 14 e 21 DAA e índice SPAD aos 10 DAA (Tabela 1).

As plantas de milho doce não apresentaram sintomas de intoxicação em resposta à aplicação do mesotrione, independentemente da dosagem ou época de aplicação do herbicida. Neste trabalho, todos os tratamentos receberam notas de descrição de sintomas de fitointoxicação na escala de 1 que, por sua vez, descreve a presença de plantas sem danos visíveis. Assim, em primeira análise, todos os tratamentos com mesotrione foram seletivos para o híbrido de milho doce Tropical Plus.

Resultados obtidos por O'Sullivan et al. (2002), ao avaliarem a tolerância de nove cultivares de milho doce ao mesotrione aplicado em pré e pós-emergência, mostraram que em pré-emergência o herbicida não causou injúria a qualquer cultivar de milho doce avaliada nas dosagens de 140 e $280 \mathrm{~g} \mathrm{ha}^{-1}$. Em pós-emergência (estádio V5), nas dosagens de $100 \mathrm{e}$ $200 \mathrm{~g} \mathrm{ha}^{-1}$, o herbicida mesotrione causou injúria em todas as cultivares, com sintomas de clorose e perda de pigmentação nas folhas, levando ao esbranquiçamento das plantas. As médias de fitointoxicação variaram entre 0 e $38 \%$ na dosagem de $100 \mathrm{~g} \mathrm{ha}^{-1}$ e entre 2 e $57 \%$ na dosagem de $200 \mathrm{~g} \mathrm{ha}^{-1}$.

Em ensaios conduzidos com milho comum por Skrzypczak et al. (2011), as plantas também se mostraram como tolerantes ao mesotrione. Não foram observados sintomas de intoxicação nos tratamentos com mesotrione aplicados de forma isolada (150 $\mathrm{g}$ ha $\left.{ }^{-1}\right)$ sobre plantas em estádio V4 a V6. Dados obtidos por Furtado (2004) em ensaio realizado em casa de vegetação demonstraram a ausência de sintomas visuais de intoxicação por mesotrione aplicado em pós -emergência (estádio V4) até duas vezes a dosagem recomendada (288 $\mathrm{g} \mathrm{ha}^{-1}$ ) em milho comum cv. BRS 2020.

Em estudo realizado por Ogliari et al. (2009), os sintomas visuais de intoxicação em plantas de milho comum tratadas com mesotrione (192 $\mathrm{g} \mathrm{ha}^{-1}$ ) em estádio V4 iniciaram-se principalmente na terceira e na quarta folha a partir dos $3 \mathrm{DAA}$. Esses sintomas foram reduzindo progressivamente a partir dos 7 DAA, e aos 12 DAA não se observou nenhuma evidência visual de intoxicação. As folhas que surgiram após a aplicação do herbicida não apresentaram sintomas.

As enzimas do citocromo P450 desempenham um importante papel na metabolização de alguns herbicidas, incluindo-se o mesotrione (Williams et al., 2008). Respostas variadas aos herbicidas metabolizados com P450 podem ser resultado de taxas desiguais de metabolismo entre híbridos de milho doce, que diferem para os alelos que regulam o citocromo P450 monoxigenase.

No que se refere ao efeito dos tratamentos sobre a altura de plantas aos 21 DAA (Tabela 2) comparados às suas respectivas testemunhas sem herbicida, essa variável-resposta apresentou efeito significativo em relação à época de aplicação. As plantas de milho doce submetidas ao mesotrione no estádio V6 apresentaram altura inferior às plantas que receberam o herbicida no estádio V3. Entretanto, para essas duas épocas, não houve diferença se comparados à aplicação em pré-emergência.

De acordo com estudo realizado por O'Sullivan et al. (2002), que avaliou a seletividade do herbicida mesotrione em cultivares de milho doce em diferentes épocas de aplicação, para as aplicações em pré-emergência do herbicida não foi constatada ne- 
Tabela 2. Altura relativa (\%) aos 21 dias após a aplicação (DAA), diâmetro de colmo relativo (\%) aos 14 e 21 DAA e índice SPAD relativo (\%) aos 10 DAA de plantas de milho doce híbrido Tropical Plus após a aplicação de dosagens crescentes do herbicida mesotrione em diferentes épocas de aplicação (pré-emergência e pós-semeadura, pós-emergência em estádio V3 e pós-emergência em estádio V6). Morrinhos-GO, 2016.

\begin{tabular}{|c|c|c|c|}
\hline \multirow{2}{*}{$\begin{array}{c}\text { Dosagem } \\
\left(\mathrm{g} \mathrm{ha}^{-1}\right)\end{array}$} & \multicolumn{3}{|c|}{ Épocas de aplicação } \\
\hline & Pré-emergência & Pós-emergência - V3 & Pós-emergência - V6 \\
\hline \multicolumn{4}{|c|}{ Altura relativa $(\%)$ - 21 DAA } \\
\hline 0 & 100,00 & 100,00 & 100,00 \\
\hline 72 & 103,24 & 106,81 & 95,69 \\
\hline 144 & 101,90 & 99,42 & 92,62 \\
\hline 288 & 100,60 & 107,37 & 96,86 \\
\hline 576 & 91,19 & 105,75 & 94,59 \\
\hline Média & $99,39 \mathrm{AB}$ & $103,87 \mathrm{~A}$ & $95,95 \mathrm{~B}$ \\
\hline \multicolumn{4}{|l|}{$\overline{\mathrm{DMS}}=6,23$} \\
\hline \multicolumn{4}{|l|}{$\mathrm{CV}(\%)=9,17$} \\
\hline \multicolumn{4}{|c|}{ Diâmetro de colmo relativo (\%) - 14 DAA } \\
\hline 0 & 100,00 & 100,00 & 100,00 \\
\hline 72 & 106,97 & 99,97 & 97,31 \\
\hline 144 & 108,48 & 108,63 & 96,96 \\
\hline 288 & 110,85 & 98,65 & 94,78 \\
\hline 576 & 98,15 & 96,21 & 94,80 \\
\hline Média & $104,89 \mathrm{~A}$ & $100,69 \mathrm{AB}$ & $96,77 \mathrm{~B}$ \\
\hline \multicolumn{4}{|l|}{$\mathrm{DMS}=5,80$} \\
\hline \multicolumn{4}{|l|}{$\mathrm{CV}(\%)=8,46$} \\
\hline \multicolumn{4}{|c|}{ Diâmetro de colmo relativo (\%) - 21 DAA } \\
\hline 0 & 100,00 & 100,00 & 100,00 \\
\hline 72 & 109,20 & 98,94 & 97,69 \\
\hline 144 & 107,64 & 108,96 & 98,85 \\
\hline 288 & 112,87 & 101,01 & 98,69 \\
\hline 576 & 102,15 & 100,16 & 95,79 \\
\hline Média & $106,37 \mathrm{~A}$ & $101,81 \mathrm{AB}$ & $98,20 \mathrm{~B}$ \\
\hline \multicolumn{4}{|l|}{$\underline{\mathrm{DMS}}=4,72$} \\
\hline \multicolumn{4}{|l|}{$\mathrm{CV}(\%)=6,79$} \\
\hline \multicolumn{4}{|c|}{ Índice SPAD relativo (\%) - 10 DAA } \\
\hline 0 & 100,00 & 100,00 & 100,00 \\
\hline 72 & 108,43 & 114,55 & 106,00 \\
\hline 144 & 109,50 & 112,96 & 100,15 \\
\hline 288 & 111,06 & 111,72 & 100,00 \\
\hline 576 & 105,98 & 117,28 & 95,98 \\
\hline Média & $106,99 \mathrm{AB}$ & $111,30 \mathrm{~A}$ & $100,43 \mathrm{~B}$ \\
\hline \multicolumn{4}{|l|}{$\mathrm{DMS}=6,84$} \\
\hline$\overline{\mathrm{CV}}(\%)=9,46$ & & & \\
\hline
\end{tabular}

Médias seguidas de mesma letra na linha não diferem estatisticamente pelo Teste de Tukey a $5 \%$ de probabilidade. 
nhuma redução com relação à altura de plantas dentre todas as cultivares avaliadas. Já para a aplicação de $200 \mathrm{~g} \mathrm{ha}^{-1}$ de mesotrione, em plantas no estádio V5, a cultivar Del Monte 2038 apresentou redução significativa de altura, o que a faria como de maior sensibilidade para aplicações em pós-emergência.

As avaliações de diâmetro de colmo realizadas aos 14 e 21 DAA (Tabela 2) apresentaram resultados semelhantes, não sendo constatada interação significativa entre os fatores, onde a variável-resposta teve efeito significativo em relação às épocas de aplicação. Tanto aos 14 quanto aos 21 DAA, considerando a média das dosagens de mesotrione avaliadas, plantas tratadas com mesotrione no estádio V6 apresentaram diâmetro de colmo inferior às plantas que receberam o herbicida em pré-emergência. Todavia, plantas tratadas com mesotrione em pré-emergência e pós-emergência (estádio V6), em média, não diferiram de plantas tratadas com mesotrione no estádio V3.

No que se refere ao efeito dos tratamentos sobre o índice SPAD aos 10 DAA foi observado efeito significativo apenas para as épocas de aplicação (Tabela 2). Em média, plantas de milho doce submetidas ao mesotrione no estádio V6 apresentaram índice SPAD inferior às plantas que receberam o herbicida no estádio V3, não havendo diferença dessas duas épocas de aplicação se comparadas à aplicação em pré-emergência.

Ogliari et al. (2009) relatam que a fotossíntese é importante na estratégia para a análise de plantas tratadas com herbicidas. Esses autores observaram que o herbicida mesotrione na dosagem de $192 \mathrm{~g} \mathrm{ha}^{-1}$, aplicado em estádio V4, reduziu a taxa fotossintética nas plantas de milho híbrido Braskalb $330 \mathrm{em} \mathrm{78 \%}$ no primeiro dia, $66 \%$ no segundo dia e $75 \%$ no terceiro dia após a aplicação do herbicida, em relação ao controle. Entretanto, aos 5 e 7 DAA, a taxa fotos- sintética nos tratamentos não apresentou diferenças significativas.

O estudo da matéria seca determina o aumento de material acumulado durante a formação de um órgão ou da planta toda, sem levar em consideração o conteúdo de água. Para a variável massa de matéria seca da parte aérea, não houve diferença significativa para os tratamentos, ou seja, não houve redução de massa de matéria seca em decorrência da aplicação do mesotrione, independentemente da dosagem ou época de aplicação do herbicida.

Resultados da avaliação de fitointoxicação e crescimento em relação ao acúmulo de massa de matéria seca da parte aérea podem confirmar a seletividade de um herbicida, principalmente em situações onde não se possuam avaliações realizadas ao final do ciclo da cultura, as quais poderiam apontar o efeito dos tratamentos sobre a produtividade. Neste estudo, apesar da redução da altura, diâmetro de colmo e índice SPAD nas plantas em estádio V6, não houve efeito sobre a massa de matéria seca, possivelmente por causa da recuperação das plantas de milho, o que nessas condições garante seletividade do herbicida mesotrione independentemente de dosagem e época de aplicação.

Em estudo realizado por Furtado (2004) com o objetivo de avaliar a seletividade do herbicida mesotrione em milho comum por meio de curvas de dosagem-resposta pode-se notar a forte tendência de se reduzir a massa de matéria seca de plantas de milho submetidas a dosagens crescentes do herbicida até a dosagem recomendada de $144 \mathrm{~g} \mathrm{ha}^{-1}$, com aproximadamente $20 \%$ de redução com relação à testemunha sem aplicação. A partir desse ponto, a perda de matéria seca se estabilizou.

Conhecer e entender as propriedades físicoquímicas dos herbicidas também é determinante em 
estudos relacionados à seletividade de herbicidas. As propriedades físico-químicas dos herbicidas determinam seu modo de aplicação e governam a dinâmica dos herbicidas no ambiente e nas plantas (Martinazzo, 2010). A dinâmica de herbicidas no solo é um fator importante a ser analisado pela capacidade de ocasionar diferentes níveis de tolerância em tratamentos com herbicidas. A partir do conhecimento das propriedades físico-químicas do herbicida relacionadas à análise de solo do experimento, foi observado que o mesotrione apresentou-se com alta capacidade de absorção pelas plantas, o que em tese seria o ideal para estudos relacionados à seletividade. Esse fator reflete, assim como os demais resultados deste trabalho, a alta capacidade do milho doce em tolerar o tratamento com o herbicida mesotrione.

Segundo Rouchaud et al. (2000), o período residual do mesotrione no solo é em torno de 120 dias. Isso é de extrema importância quando se trata de aplicações em pré-emergência, pois quanto maior for o período residual, maior será o intervalo de controle de plantas daninhas na área. Porém, a rotação de cultivos é um aspecto a ser considerado para a aplicação de determinados herbicidas. O herbicida mesotrione, dependendo da época de aplicação, dosagem aplicada, textura do solo, porcentagem de matéria orgânica e precipitação pluvial, pode apresentar efeito residual ou carryover para a cultura sucessora, podendo comprometer estabelecimento, crescimento, produtividade e qualidade do produto final.

O herbicida mesotrione ainda não é registrado para aplicações em pré-emergência na cultura do milho no Brasil, apesar de vários estudos já relatarem sua seletividade à cultura nessa modalidade de aplicação e sua eficácia no controle inicial de plantas daninhas. Mais estudos, em condições de casa de vegetação e campo, acerca da eficácia e seletividade de mesotrione, são demandados, em razão dos diferentes resultados obtidos entre os diversos trabalhos encontrados na literatura. Além disso, sua seletividade deve ser avaliada em diversos híbridos, tendo em vista a tolerância diferencial que pode existir entre esses.

\section{Conclusão}

O mesotrione apresenta seletividade à cultura do milho doce híbrido Tropical Plus até quatro vezes a dosagem recomendada do herbicida (576 $\mathrm{g} \mathrm{ha}^{-1}$ ), tanto em aplicações em pré-emergência quanto em pós-emergência (estádios V3 e V6).

\section{Agradecimento}

À Fundação de Amparo à Pesquisa do Estado de Goiás (FAPEG), pelo suporte financeiro por meio da bolsa de estudos disponibilizada.

\section{Referências}

EUROPEAN WEED RESEARCH COUNCIL. Report of the $3^{\text {rd }}$ and $4^{\text {th }}$ meetings of EWRC. Oxford, 1964. $88 \mathrm{p}$.

FERREIRA, D. F. Sistema de análise de variância (SISVAR): versão 4.6. Lavras: Universidade Federal de Lavras, 1999.

FURTADO, D. A. S. Seletividade e eficácia agronômica do herbicida mesotrione na cultura do milho. 2004. 68 f. Dissertação (Metrado em Fitotecnia) - Universidade Federal de Lavras, Lavras, 2004.

KARAM, D.; MELHORANÇA, A. L.; OLIVEIRA, M. F. de; SILVA, J. A. A. Plantas daninhas. In: CRUZ, J. C. (Ed.). Cultivo do milho. 6. ed. Sete Lagoas: Embrapa Milho e Sorgo, 2010. (Embrapa Milho e Sorgo. Sistemas de Produção, 1). 
MARTINAZZO, R. Dinâmica da atrazine e mesotrione em solos: degradação acelerada, sorção e implicações ambientais. 2010. 114 f. Tese (Doutorado em Ciência do Solo) - Universidade Federal do Rio Grande do Sul, Porto Alegre, 2010.

MINOLTA, C. Manual for chlorophyll meter SPAD-502. Osaka: Minolta Radiometric Instruments Divisions, 1989. $22 \mathrm{p}$.

NAKAGAWA, A. C. S.; MARINO, T. P.; LOPES, K. B.; DALTO, P. G.; KRAUSE, M. D.; CAVAlCANTE, A. P.; DIAS, H. A. C. Potencial agronômico de populações de milho superdoce portadoras do gene Brittle-2. In: CONGRESSO NACIONAL DE MILHO E SORGO, 29., 2012, Águas de Lindóia. Diversidade e inovações na era dos transgênicos: resumos expandidos. Campinas: Instituto Agronômico; Sete Lagoas: Associação Brasileira de Milho e Sorgo, 2012. 1 CD-ROM.

OGLIARI, J.; FREITAS, S. P.; RAMOS, A. C.; BRESSAN-SMITH, R. E.; FAÇANHA, A. R. Sistemas primários de transporte de prótons integram os mecanismos de desintoxicação do mesotrione em plantas de milho. Planta Daninha, Viçosa, MG, v. 27, n. 4, p. 799-807, 2009.

DOI: $10.1590 / \mathrm{S} 0100-83582009000400018$.

OLIVEIRA JÚNIOR, R. S.; CONSTANTIN, J.; INOUE, M. H. Seletividade de herbicidas para culturas e plantas daninhas. In: OLIVEIRA JÚNIOR, R. S.; CONSTANTIN, J.; INOUE, M. H. (Ed.). Biologia e manejo de plantas daninhas. Curitiba: Omnipax, 2011. cap. 10, p. 244-262.

O'SULLIVAN, J.; ZANDSTRA, J.; SIKKEMA, P. Sweet corn (Zea mays) cultivar sensitivity to mesotrione. Weed Technology, Champaign, v. 16, n. 2, p. 421-425, 2002.

DOI:10.1614/0890-037X(2002)016[0421:SCZMCS]2.0.CO;2.

PEREIRA FILHO, I. A.; TEIXEIRA, F. F. (Ed.). O cultivo do milho-doce. Brasília, DF: Embrapa, 2016. 298 p.
RODRIGUES, B. N.; ALMEIDAF. S. Guia de herbicidas. 6. ed. Londrina: Ed. dos Autores, 2011. 697 p.

ROUCHAUD, J.; NEUS, O.; COOLS, K.; BUCKLE, R. Dissipation of the triketone mesotrione herbicide in the soil of the soil of corn crops grown on different soil types. Environmental Toxicology and Chemistry, New York, v. 77,n.2,p. 31-40,2000. DOI: 10.1080/02772240009358936.

SANTOS, H. G. dos; JACOMINE, P. K. T.; ANJOS, L. H. C. dos; OLIVEIRA, V. A. de; LUMBRERAS, J. F.; COELHO, M. R.; ALMEIDA, J. A. de; CUNHA, T. J. F.; OLIVEIRA, J. B. de. Sistema brasileiro de classificação de solos. 3. ed. rev. e ampl. Brasília, DF: Embrapa, 2013. $353 \mathrm{p}$.

SAS INSTITUTE. Statistical Analysis System: procedure guide for personal computers: version 5. Cary, 1999.

SKRZYPCZAK, G. A.; SOBIECH, L.; WANIOREK, W. Evaluation of the efficacy of mesotrione plus nicosulfuron with additives as tank-mixtures used for weed control in maize (Zea mays L.). Journal of Plant Protection Research, Poznan, v. 51, n. 3, p. 300-305, 2011.

DOI: $10.2478 / \mathrm{v} 10045-011-0049-1$.

WILLIAMS, M. M. Planting date influences critical period of weed control in sweet corn. Weed Science, Champaign, v. 54, n. 5, p. 928-933, 2006.

DOI: $10.1614 / \mathrm{WS}-06-005 \mathrm{R} .1$.

WILLIAMS, M. M.; RABAEY T. L.; BOERBOOM, C. M. Residual weeds of sweet corn in the north central region. Weed Technology, Champaign, v. 22, n. 4, p. 646-653, 2008. DOI: 10.1614/WT-08-012.1.

ZUCHARELI, C.; PANOFF, B.; PORTUGAL, G.; FONSECA, I. C. B. Doses e épocas de aplicação de nitrogênio em cobertura na qualidade fisiológica de sementes de milho doce. Revista Brasileira de Sementes, Londrina, v. 34, n. 3, p. 480-487, 2012.

DOI: $10.1590 / \mathrm{S} 0101-31222012000300016$. 